\title{
ALTERAÇÕES EM MATERIAIS RESTAURADORES CAUSADAS PELOS GÉIS FLUORETADOS ACIDULADOS: UMA REVISÃO INTEGRATIVA
}

\section{Silvia Letícia Sena Ferreira ${ }^{1}$; Hervânia Santana da $\operatorname{Costa}^{2}$; Carlos Sampaio de Santana Neto $^{3}$ e Ana Rita Duarte Guimarães ${ }^{4}$}

1 Bolsista FAPESB, Graduando em Odontologia, Universidade Estadual de Feira de Santana, e-mail: silvialsena@gmail.com 2 Orientador, Departamento de Saúde, Universidade Estadual de Feira de Santana, e-mail: hervacosta@ gmail.com

3 Participante do projeto, Departamento de Saúde, Universidade Estadual de Feira de Santana, e-mail: cs.neeto@gmail.com

4 Participante do projeto, Departamento de Saúde, Universidade Estadual de Feira de Santana, e-mail: ardg1999@gmail.com

\section{PALAVRAS-CHAVE: Fluoreto de Fosfato Acidulado; Materiais Dentários; Saúde Bucal. INTRODUÇÃO}

Na cavidade bucal alguns fatores podem atuar sobre a superfície das restaurações, diminuindo a microdureza, com consequente aumento da rugosidade que favorece a colonização bacteriana em pacientes com higiene bucal precária contribuindo para o insucesso da restauração. Dentre os fatores capazes de alterar a superfície dos materiais restauradores temos a aplicação tópica de flúor (FIROOZMAND; ARAÚJO, 2006). De acordo com a literatura, o uso do flúor gel acidulado pode aumentar a rugosidade superficial, alterar a cor ou interferir na microdureza do material restaurador, mas com o uso do flúor gel neutro no tempo adequado pode ser que as características de superfície não sofram alterações ou possam se apresentar reduzidas em menor intensidade (LEITE, 2013). A porosidade superficial destes materiais facilita a penetração de corantes e ácidos, acúmulo de biofilme dental e consequentemente a hidrólise (FIROOZMAND; ARAÚJO, 2006). Segundo Botta (2010) a adesão bacteriana acontece principalmente em áreas ásperas das estruturas naturais do dente e em materiais restauradores.

Diante das desvantagens que a literatura nos traz sobre o uso do flúor gel acidulado sobre os materiais restauradores e com o advento da Odontologia Baseada em Evidências, faz-se necessário responder alguns questionamentos: qual o nível de evidência científica destes estudos que relatam as alterações causadas nos materiais restauradores pelo uso do flúor gel acidulado? Estas alterações são confirmadas por estudos de maior nível de evidência cientifica? A proposta deste estudo foi investigar o nível de evidência dos estudos publicados nesta área.

\section{MATERIAIS E MÉTODOS}

Para este estudo foi aplicado uma metodologia do tipo revisão integrativa que possibilita a apropriação de um conhecimento mais abrangente. Foi realizado o levantamento de dados de pesquisas primárias, agrupando os estudos ordenada e sistematicamente. Os critérios de inclusão foram: estudos encontrados sobre o tema em tela divulgados nos idiomas português, inglês e espanhol, no período de 2010 a 2017. Os descritores utilizados foram "Acidulated Phosphate Fluoride" e "Dental Materials" nas bases de dados Portal Regional da BVS, Portal Periódico CAPES e IBICT. Não foram incluídos os trabalhos indisponíveis na íntegra e que não atenderam aos critérios de inclusão. Os artigos encontrados foram fichados e a categorização foi feita com base na tabela do Nível de Evidência por Tipo de Estudo "Oxford Centre for Evidence-based Medicine, 2001" (AMB-CFM, 2002).

\section{RESULTADOS E DISCUSSÃO}

A partir da pesquisa foram selecionados 15 artigos. Suas informações pertinentes a esta pesquisa estão apresentadas na Tabela 1 . 
Tabela 1- Estudos classificados segundo o Nível de evidência Científica por Tipo de Estudo "Oxford Centre for Evidence-based Medicine, 2001", Feira de Santana, Bahia, 2017 (N = 15)

\begin{tabular}{|c|c|c|c|c|c|c|}
\hline Autor & Ano & Objetivo & $\begin{array}{l}\text { Tipo de } \\
\text { Estudo }\end{array}$ & $\begin{array}{l}\text { Nível de } \\
\text { Evidência }\end{array}$ & $\begin{array}{l}\text { Material } \\
\text { Flúor }\end{array}$ & Conclusões \\
\hline Botta et al. & 2010 & $\begin{array}{l}\text { FFA na Ra superficial } \\
\text { do esmalte dentário e } \\
\text { diferentes materiais } \\
\text { restauradores. }\end{array}$ & In vitro & 5 & $\begin{array}{l}\text { FFA } 1,23 \% \\
4 \text { min e } 24 \mathrm{~h} .\end{array}$ & $\begin{array}{l}\text { O FFA aumentou a Ra da superfície do esmalte e } \\
\text { diminuiu a Ra superficial do CIV modificado por } \\
\text { resina e da resina composta microhíbrida com } \\
\text { flúor. A Ra superficial da resina composta } \\
\text { nanoparticulada não foi modificada. }\end{array}$ \\
\hline $\begin{array}{l}\text { Avsar e } \\
\text { Tuloglu }\end{array}$ & 2010 & $\begin{array}{l}\mathrm{NNaF} \text { e FFA sobre a } \\
\text { Ra da superfície de } \\
\text { materiais restauradores. }\end{array}$ & In vitro & 5 & $\begin{array}{l}\text { FFA a } \\
1,23 \% \text { e } \\
\mathrm{NNaF} \text { a } \\
2 \%\end{array}$ & $\begin{array}{l}\text { Tanto os compômeros quanto o CIV modificado } \\
\text { mostraram Ra superficial significativamente } \\
\text { maior após aplicação de gel APF. }\end{array}$ \\
\hline $\begin{array}{l}\text { Ccahuana et } \\
\text { al. }\end{array}$ & 2010 & $\begin{array}{l}\text { Degradação superficial } \\
\text { da exposição ao gel } \\
\text { FFA na cerâmica de } \\
\text { matriz vítrea em função } \\
\text { do tempo. }\end{array}$ & In vitro & 5 & $\begin{array}{l}\text { FFA a } \\
1,23 \% \text { por } \\
4 \text { min e } 60 \\
\text { min. }\end{array}$ & $\begin{array}{l}\text { A análise qualitativa mostrou mudanças na } \\
\text { superfície em graus variados em todas as } \\
\text { cerâmicas. }\end{array}$ \\
\hline $\begin{array}{l}\text { Gill e } \\
\text { Pathak }\end{array}$ & 2010 & $\begin{array}{l}\text { Efeito de fluoretos } \\
\text { tópicos na microdureza } \\
\text { de CIVs convencionais, } \\
\text { CIV convencional de } \\
\text { alta viscosidade e CIVs } \\
\text { modificados por resina. }\end{array}$ & In vitro & 5 & $\begin{array}{l}\text { FFA a } \\
1,23 \% . \mathrm{e} \\
\mathrm{NNaF} 2 \% \\
\text { por } 4 \text { min. }\end{array}$ & $\begin{array}{l}\text { O uso de FFA } 1,23 \% \text { pode ser prejudicial para a } \\
\text { durabilidade a longo prazo das restauraçôes de } \\
\text { ionômero de vidro. }\end{array}$ \\
\hline $\begin{array}{l}\text { Hosoya et } \\
\text { al. }\end{array}$ & 2011 & $\begin{array}{l}\text { FFA na Ra superficial, } \\
\text { brilho e cor de resinas } \\
\text { compostas. }\end{array}$ & In vitro & 5 & $\begin{array}{l}\text { FFA por } \\
\text { 30min. }\end{array}$ & $\begin{array}{l}\text { A aplicação de gel FFA não causou deterioração } \\
\text { perceptivel e mudança de cor de resinas } \\
\text { compostas. }\end{array}$ \\
\hline Yeh et al. & 2011 & $\begin{array}{l}\text { Demonstrar que as } \\
\text { superfícies de } \\
\text { nanocompósitos não } \\
\text { foram afetadas por } \\
\text { alguns géis de FFA e } \\
\text { possíveis mecanismos } \\
\text { subjacentes. }\end{array}$ & In vitro & 5 & $\begin{array}{l}\text { FFA } 1,23 \% \\
\text { (60 Second } \\
\text { Taste Gel, } \\
\text { Topex, and } \\
\text { Zap) e } \\
\text { NNaF } \\
0,9 \% .\end{array}$ & $\begin{array}{l}\text { Recomenda-se que os pacientes recebam géis } \\
\text { contendo gel de FFA para prevenir a cárie como } \\
\text { parte de seu cuidado bucal sem os efeitos } \\
\text { adversos em seus compósitos restaurados. }\end{array}$ \\
\hline $\begin{array}{l}\text { Topaloglu- } \\
\text { Ak et al. }\end{array}$ & 2012 & $\begin{array}{l}\text { Efeitos de } 1 \text { e } 4 \\
\text { minutos de aplicação } \\
\text { de } 1,23 \% \text { de FFA e } 1 \\
\text { minuto de aplicação de } \\
1 \% \text { de TiF4 nos } \\
\text { materiais restauradores. }\end{array}$ & In vitro & 5 & $\begin{array}{l}1,23 \% \text { de } \\
\text { FFA } 1 \text { e } \\
4 \text { min e } 1 \% \\
\text { de TiF4 por } \\
1 \text { min. }\end{array}$ & $\begin{array}{l}\text { Potenciais efeitos adversos das aplicações de FFA } \\
\text { e TiF4 podem ser dependentes de material. Este } \\
\text { deve ser selecionado de acordo com o tipo, } \\
\text { frequência e tempo de aplicação da fluoretação. }\end{array}$ \\
\hline $\begin{array}{l}\text { Ozdemir- } \\
\text { Ozenen et al }\end{array}$ & 2013 & $\begin{array}{l}\text { Efeito de uma única } \\
\text { aplicação de dois } \\
\text { agentes tópicos de } \\
\text { flúor; NNaF e APF em } \\
\text { materiais restauradores. }\end{array}$ & In vitro & 5 & $\begin{array}{l}\mathrm{NNaF} \text { a } 2 \% \\
\text { e FFA a } \\
1,23 \% \text { por } \\
1 \text { min e } \\
4 \mathrm{~min} .\end{array}$ & $\begin{array}{l}\text { A alteração nos valores de Ra superficial é } \\
\text { dependente do material e tempos de aplicação } \\
\text { mais curtos ( } 1 \text { min) podem ser preferidos. }\end{array}$ \\
\hline $\begin{array}{l}\text { Wang e } \\
\text { Huang }\end{array}$ & 2014 & $\begin{array}{l}\text { Examinar o efeito de } \\
\text { descoloração do gel } \\
\text { FFA em vários níveis } \\
\text { de concentração em } \\
\text { restaurações de CIV. }\end{array}$ & In vitro & 5 & $\begin{array}{l}\text { FFA } 1,23 \% \\
\text { por } 4 \mathrm{~min} .\end{array}$ & $\begin{array}{l}\text { A descoloração do CIV foi associada à } \\
\text { concentração e frequência da aplicação do gel } \\
\text { FFA nos dentes humanos naturais extraídos. }\end{array}$ \\
\hline $\begin{array}{l}\text { Mujeeb et } \\
\text { al. }\end{array}$ & 2014 & $\begin{array}{l}\text { Efeito do flúor tópico } \\
\text { aplicado } \\
\text { profissionalmente } \\
\text { sobre a dureza } \\
\text { superficial de três } \\
\text { diferentes restaurações } \\
\text { à base de compósitos. }\end{array}$ & In vitro & 5 & $\begin{array}{l}\text { FFA } \\
(1,23 \%), \\
\text { solução de } \\
\text { flúoreto de } \\
\text { sódio e } \\
\text { NNaF } \\
(0,9 \%) \text {. }\end{array}$ & $\begin{array}{l}\text { Toda a aplicação tópica de flúor mostrou efeito } \\
\text { deteriorativo. } \\
\text { A deterioração da superfície e diminuição da } \\
\text { microdureza foi dependente do } \mathrm{pH} \text { do flúor } \\
\text { tópico. }\end{array}$ \\
\hline
\end{tabular}




\begin{tabular}{|c|c|c|c|c|c|c|}
\hline \multicolumn{7}{|c|}{ Continuação - Tabela 1} \\
\hline $\begin{array}{l}\text { Mundim } e t \\
\text { al. }\end{array}$ & 2014 & $\begin{array}{l}\text { Ação de diferentes } \\
\text { soluções de flúor na } \\
\text { estabilidade de cor e Ra } \\
\text { superficial de } \\
\text { compósitos } \\
\text { odontológicos. }\end{array}$ & In vitro & 5 & $\begin{array}{l}\text { FFA a } \\
1,23 \%, \\
\text { NNaF a } 2 \% \\
\text { e solução } \\
\text { de flúor a } \\
0,05 \% \\
4 \text { min. }\end{array}$ & $\begin{array}{l}\text { As alterações de cor e Ra dos compósitos foram } \\
\text { clinicamente aceitáveis e dependentes dos } \\
\text { materiais. }\end{array}$ \\
\hline $\begin{array}{l}\text { Khosla, } \\
\text { Kuriakose e } \\
\text { Suderasen }\end{array}$ & 2014 & $\begin{array}{l}\text { Alterações } \\
\text { micromorfológicas da } \\
\text { superfície do CIV } \\
\text { convencional e CIV } \\
\text { alta resistência e alta } \\
\text { viscosidade. }\end{array}$ & In vitro & 5 & $\begin{array}{l}\text { FFA a } \\
1,23 \% \text { por } \\
4 \mathrm{~min} .\end{array}$ & $\begin{array}{l}\text { Gel FFA causou desgaste erosivo nos CIVs. } \\
\text { Recomenda-se a aplicação de verniz de CIV antes } \\
\text { da aplicação do gel FFA. }\end{array}$ \\
\hline $\begin{array}{l}\text { Thomas et } \\
\text { al. }\end{array}$ & 2015 & $\begin{array}{l}\text { Desempenho de } \\
\text { materiais de zircônia } \\
\text { sob ambiente oral ácido } \\
\text { simulado. }\end{array}$ & In vitro & 5 & $\begin{array}{l}\text { FFA a } \\
1,23 \% \text { e } \\
0,123 \% \text { por } \\
24 \mathrm{~h} \mathrm{e} 11 \mathrm{~d} .\end{array}$ & $\begin{array}{l}\text { O meio ácido não foi capaz de desencadear o } \\
\text { fenômeno do envelhecimento. Foi detectada } \\
\text { degradação superficial. }\end{array}$ \\
\hline Lin e Huang & 2015 & $\begin{array}{l}\text { Potencial de coloração } \\
\text { da espuma de FFA em } \\
\text { restaurações. }\end{array}$ & In vitro & 5 & $\begin{array}{l}\text { FFA } 1,23 \% \\
\text { por } 4 \mathrm{~min} .\end{array}$ & $\begin{array}{l}\text { Este estudo sugeriu implicações estéticas ao } \\
\text { aplicar fluoretos nos dentes restaurados. O CIV } \\
\text { convencional foi mais suscetível à coloração. }\end{array}$ \\
\hline $\begin{array}{l}\text { Theodoro et } \\
\text { al. }\end{array}$ & 2017 & $\begin{array}{l}\text { Resistência ao desgaste } \\
\text { e à compressão de } \\
\text { cerâmicas } \\
\text { odontológicas. }\end{array}$ & In vitro & 5 & $\begin{array}{l}\text { FFA a } \\
1,23 \% \text { e } \\
\text { NNaF a } \\
2 \%\end{array}$ & $\begin{array}{l}\text { Todas as cerâmicas testadas desgastam menos em } \\
\text { gel neutro. }\end{array}$ \\
\hline
\end{tabular}

CIV: Cimento de Ionômero de Vidro; Ra: Rugosidade; FFA: Flúoreto de Fosfato Acidulado; NNaF: Fluoreto de Sódio Neutro

Os artigos encontrados são estudos in vitro indicando baixo nível de evidência científica. A maioria identificou alterações nos materiais restauradores após o uso das substâncias contendo flúor. Alterações essas que abrangem coloração, rugosidade superficial, brilho, microdureza, desgaste entre outras e dependiam do tempo, da frequência de aplicação e da concentração das substâncias fluoretadas (AVSAR; TULOGLU, 2010; CCAHUANA et al., 2010; GILL; PATHAK, 2010; OZDEMIR-OZENEN et al., 2013;WANG; HUANG, 2014; MUJEEB et al., 2014; KHOSLA; KURIAKOSE; SUDERASEN, 2014; THOMAS et al., 2015; LIN; HUANG, 2015).

Grande parte dos estudos que utilizaram diferentes substâncias em diferentes concentrações concluiu que o flúor gel acidulado $(1,23 \%)$ induziu maiores alterações nos materiais restauradores (AVSAR; TULOGLU, 2010; GILL; PATHAK, 2010; YEH et al., 2011; MUJEEB et al., 2014). Segudo Mujeeb e colaboradores (2014) a deterioração da superfície e a diminuição da microdureza foi dependente do $\mathrm{pH}$ do flúor tópico. Porém, houve resultados de estudos que sugeriram que as restaurações feitas com diferentes materiais podem sofrer alterações em sua estrutura mesmo quando da utilização do flúor gel neutro $(2 \%, 0,9 \%)$ e dos enxaguatórios bucais $(0,05 \%)$ que apresentam menor concentração de flúor (OZDEMIR-OZENEN et al., 2013; MUNDIM et al., 2014).

Dos materiais restauradores, os cimentos de ionômero de vidro convencionais foram os que apresentaram maiores alterações à exposição a soluções fluoretadas (BOTTA et al. 2010; GILL; PATHAK, 2010; LIN; HUANG, 2015). Estas alterações podem ser prejudiciais à integridade das restaurações com CIV ao longo prazo (GILL; PATHAK, 2010), mas corroboram para uma das vantagens e indicações do uso deste material no controle de lesões de cárie ativa, quando se espera que o material restaurador funcione com uma esponja que absorva flúor e libere para o meio bucal. A fim de amenizar as alterações neste material restaurador (CIV), Khosla, Kuriakose e Suderasen (2014) recomendam o uso de uma proteção sobre o cimento de ionômero de vidro previamente ao tratamento com o gel acidulado para proteção da restauração. 
As restaurações com resina composta parecem se comportar mais adequadamente frente à ação do flúor gel acidulado. Yeh e colaboradores (2011) indicam que os pacientes recebam este tratamento para prevenir a doença cárie sem os efeitos adversos em restaurações de resina composta. Ozdemir-Ozenen e colaboradores (2013) sugerem um minuto como o tempo aceitável para esta aplicação.

Embora se tenha todos esses resultados, ressalta-se que estudos in vivo são necessários, pois, além do material restaurador e das substâncias fluoretadas, há outros fatores que podem interferir nas restaurações dentárias no meio bucal, como temperatura, enzimas, biofilme dental e fatores mecânicos (THOMAS et al., 2015).

\section{CONSIDERAÇÕES FINAIS}

$\mathrm{Na}$ atualidade, recomenda-se uma prática odontológica com base em evidências científicas. Com relação às alterações causadas pelo uso do flúor gel acidulado sobre os materiais restauradores há um baixo nível de evidência científica.

\section{REFERÊNCIAS}

AMB-CFM. Associação Médica Brasileira e Conselho Federal de Medicina. Projeto Diretrizes. 9p, Brasília, 2002. Disponível em: 〈http://www.portalmedico.org.br/diretrizes/100_diretrizes/Texto_Introdutorio.pdf〉. Acesso em: 30/03/2016.

AVSAR, A.; TULOGLU, N. Effect of different topical fluoride applications on the surface roughness of a colored compomer. J Appl Oral Sci,v. 8, n.2, p. 171-7, 2010.

BOTTA, A. C. et al. Influence of topical acidulated phosphate fluoride on surface roughness of human enamel and different restorative materials. Rev. odonto ciênc., Porto Alegre, v. 25, n. 1, p. 83-87, 2010.

CCAHUANA, V.Z.S., et al. Discolouration of Glass-Ionomer Cement at Different Fluoride Concentration Levels. . J Appl Oral Sci. v.18, n.2, p. 155-65.2010.

FIROOZMAND, L. M.; ARAÚJO, M. A. M. Ação do flúor fosfato acidulado 1.23\% sobre a resina composta: microdureza. Cienc Odontol Bras, v. 9, n. 4, p 27-34, out./dez, 2006.

GILL, N.C.; PATHAK, A. Comparative evaluation of the effect of topical fluorides on the microhardness of various restorative materials: An in vitro study. Journal of Indian Society of Pedodontics and Preventive Dentistry. v.28, n.3. Jul -Set, 2010.

HOSOYA, et al. Effects of acidulated phosphate fluoride gel application on surface roughness, gloss and colour of different type resin composites. Journal of dentistry, v. 3. p. 700-706, 2011 .

KHOSLA, E.; Sobha Kuriakose, S.; Suderasen, C."Surface micromorphological changes of glass ionomer following application of $1,23 \%$ acidulated phosphate fluoride: A scanning electron microscope study. Indian Journal of Dental Research, v. 25, n. 4, p. 493. 2014.

LEITE, E. L. et al. Avaliação in vitro da liberação e da recarga de flúor em cimentos de ionômero de vidro. Rev. odontol. UNESP, Araraquara, v. 42, n. 1, p. 25-30, Fev. 2013.

LIN, D; HUANG, B. Staining potential of acidulated phosphate fluoride (APF) foam on dental restorations in vitro. J Conserv Dent. Jan-Fev; v.18, n.1. p. 30-33. 2015.

MUJEEB, A. et al. In vitro Evaluation of Topical Fluoride $\mathrm{pH}$ and their effect on Surface Hardness of Composite Resin-based Restorative Materials. The Journal of Contemporary Dental Practice, Mar.-Abril;v.15, n.2, 190-194, 2014.

MUNDIN, F. M. et al. Effect of fluoride solutions on color and surface roughness of dental composites. RFO, Passo Fundo, v. 19, n. 1, p. 77-82, jan./abr. 2014.

OZDEMIR-OZENEN, D. et al. Surface roughness of fluoride-releasing restorative materials after topical fluoride application. European Journal of Paediatric Dentistry. v.14/1. 2013.

THEODORO, G. T. et al. Wear resistance and compression strength of ceramics tested in fluoride environments. Journal of the Mechanical Behavior of Biomedical Materials. http://dx.doi.org/10.1016/j.jmbbm.2016.09.039. 2017.

THOMAS, A. et al. Corrosion behavior of zirconia in acidulated phosphate fluoride. J Appl Oral Sci. v. 24, n.1, p. 52-60, 2016.

TOPALOGLU-AK, A. et al. Microhardness and Surface Roughness of Glass Ionomer Cements after APF and TiF4 Applications. J Clin Pediatr Dent. v.37, n.1. p. 45-52, 2012.

WANG, E.; HUANG, B. Discolouration of Glass-Ionomer Cement at Different Fluoride Concentration Levels. OHDM - Vol. 13 - No. 2 - June, 2014.

YEH, S. T. et al. The roughness, microhardness, and surface analysis of nanocomposites after application of topical fluoride gels. Dental materials. n.26. p. 187-196. 2011. 